\title{
OUTBREAK OF BOVINE PAPULAR STOMATITIS WITH CONCURRENT CRYPTOSPORIDIOSIS IN A DAIRY HERD IN TURKEY
}

\author{
S. SENTURK ${ }^{1}$, S. CATIK ${ }^{1}$, E. M. TEMIZEL ${ }^{1} \&$ O. OZYIGIT ${ }^{2}$ \\ ${ }^{1}$ Department of Internal Medicine; ${ }^{2}$ Department of Pathology, \\ Faculty of Veterinary Medicine, Uludag University, Bursa, Turkey
}

\section{Summary}

Senturk, S., S. Catık, E. M. Temizel \& O. Ozyigit, 2016. Outbreak of bovine papular stomatitis with concurrent cryptosporidiosis in a dairy herd in Turkey. Bulg. J. Vet. Med., 19, No $1,78-83$.

Bovine papular stomatitis (BPS) is a viral disease of cattle characterised by proliferative and pustular lesions on muzzle, nostrils and buccal mucosa. BPS has a low mortality rate, however can cause important economical impact to dairy industry. Cryptosporidiosis is a disease calves characterised by yellow, watery and mucus containing diarrhoea. Etiopathogenesis of both diseases are closely related with the immune status of the host. The aim of the presented study was to document the first case of BPS infection with concurrent cryptosporidiosis in calves. Fifteen calves aged between 3-6 weeks from a dairy herd in Turkey showed clinical signs such as diarrhoea and ocular-nasal seromucous discharges. Clinical examination of the calves revealed that they were suffering from stomatitis characterised by proliferative lesions. Lesions were removed surgically for histopathological examination. Calves were treated with spiramycin and an immunomodulator (Zylexis ${ }^{\circledR}$, Pfizer, Istanbul, Turkey). All calves were cured following the treatment. Histopathological examination revealed findings consistent with poxvirus infections such as ballooning and degeneration of the epithelial cells and cytoplasmic viral inclusions. Results of the presented study indicate that BPS is an infectious disease that must be considered as a secondary disease in Cryptosporidium infections. Zoonotic nature of both diseases makes the problem threatening for public health.

Key words: bovine papular stomatitis, calf, cryptosporidiosis, diarrhoea, treatment, zoonotic nature

Bovine papullar stomatitis (BPS) is a viral disease of cattle. The causative agent of BPS is a virus member of family Poxviridae in genus Poxvirinae (Fabiano et al., 2012). Clinical findings of BPS are characterised by pustular and proliferative lesions on muzzle, nostrils and buccal mucosa. BPS virus generally causes lesions only in immunocompromised animals or in calves suffering from a concurrent disease (Radostits et al., 2006a; Seifi et al., 2000; Oem et al., 2013). Although disease has low mortality because of mild clinical signs, secondary bacterial infec- 
tions could aggravate the clinical findings resulting in important economic losses. Mouth lesions prevent calves from suckling and by infecting the udders of adult cattles causes ulcerative lesions and occasionally dried crusts on the udders. Affected cows do not allow milking due to local pain of the udders, milk production decreases and sometimes secondary mastitis occurs in these animals (Fabiano et al., 2013). Zoonotic Parapoxvirus infections can cause nodules and pustules generally on the hands, face and arms of farmers and milkers (Oem et al., 2013).

Cryptosporidiosis is another important disease of calves caused by Cryptosporidium parvum protozoa of genus Cryptosporidium. Disease is characterised by yellow, watery diarrhoea that contains mucus (Radostits et al., 2006b; Chalmers et al., 2013). In cattle, Cryptosporidium parvum frequently causes mild to severe diarrhoea and weakness particularly in neonates. In humans clinical consequences of cryptosporidiosis are generally associated with an immunocompromised health status such as acquired immune deficiency syndrome, leukaemia and immunosuppressive therapy. Poor hygiene conditions increase the risk of contamination in undernourished people. Veterinarians, paraveterinarians, farmers and children are predisposed to occupational exposure. Symptoms of cryptosporidiosis vary according to the immune status of the people. The clinical condition changes from self-limiting gastrointestinal symptoms in immunocompetent people to chronic disease with fatal outcome in immunocompromised subjects (Yosra et al., 2013).

Despite the low mortality rate, cryptosporidiosis causes important economic losses in cattle industry due to marked loss of body weight of calves and the dis- ease has zoonotic importance as BPS. The presented study reports an outbreak of BPS with concurrent cryptosporidiosis.

The study was conducted in Holstein Friesian beef breeding farm around the town of Tire in İzmir, Turkey. There were 20 calves in the herd and all were examined for BPS and cryptosporidiosis. Clinically, 15 calves 3-6 weeks of age were found to be suffering from different degrees of stomatitis and yellow, watery and mucus-containing diarrhoea. In 5 calves there was no clinical symptom associated with BPS or cryptosporidiosis. The body temperature, pulse and respiratory rates, character of stomatitis, capillary refill time (CFT), peripheral pulse quality, dehydration degrees and mental status were determined by clinical examination. The $\mathrm{pH}$ of faeces was measured by a $\mathrm{pH}$ meter. A commercial immunochromatographic rapid test (Speed ${ }^{\circledR}$ V-DIAR 4, Virbac) was used to determine the four main pathogens responsible for the calf diarrhea including Coronavirus, Cryptosporidium parvum, Rotavirus and Escherichia coli. Two lesions of a calf were removed surgically for histopathological examination.

Calves suffering from cryptosporidosis were treated with spiramycin (Spirovet ${ }^{\circledR}$, CEVA Animal Health, Istanbul, Turkey) administered by intramuscular route to each calf at a dosage of $10 \mathrm{mg} / \mathrm{kg}$ of body weight, twice a day for 5 days. Fluid therapy was administered to 4 severely dehydrated calves. Additionally, an immunomodulator consisting of inactivated parapox ovis virus D 1071 (Zylexis ${ }^{\circledR}$, Pfizer, Istanbul, Turkey) was applied intramuscularly at $2 \mathrm{~mL}$ for each animal on days 1,2 and 10 in order to eliminate the possible immunosuppression in calves.

All calves in this study showed mild mental depression, ptyalism, and decrease in suckling reflex, stomatitis and diarrhoea 
of different severity. The other observed clinical findings included mild dyspnea, ocular and nasal sero-mucous discharges. Eleven calves had pneumonia based on auscultation of lungs. The body temperatures of 15 animals were within normal limits (mean: $38.7 \pm 0.4{ }^{\circ} \mathrm{C}$, reference range: $38-39.2{ }^{\circ} \mathrm{C}$ ) and the respiratory rates in all calves were above normal (mean: $52 \pm 4$ breaths/min, reference range: 10-30 breaths/min). In 4 calves dehydration degrees were between 9-10\%. These calves were also mildly depressed and after treatment their mental status turned to normal. Other calves had mild dehydration (6-8\% dehydration) and fluid therapy was not administered. CFT fluctuated between 1 to $4 \mathrm{~s}$. Pulse rates were within the normal reference range however in the four severely dehydrated calves were increased (mean: $86 \pm 12 \mathrm{~min}^{-1}$, reference range: $70-90 \mathrm{~min}^{-1}$ ). Peripheral pulse quality was normal in mildly dehydrated calves whereas severely dehydrated ani- mals had weak peripheral pulse. The $\mathrm{pH}$ values of faeces were between 6 and 7 .

After careful examination of the mouth, it was determined that affected animals had stomatitis. Lesions were confined to the muzzle in the ventral margins of the nares, on the buccal mucosa, inside the lips, and especially on the hard palate (Fig. 1 and 2). Lesions were absent on the dorsum of the tongue. Other causes of stomatitis, such as mucosal disease, foot and mouth disease (FMD), IBR were also considered in clinical diagnosis. The rate of spread and some clinical symptoms differed from these diseases. Lesions in calves were not necrotic, ulcerative and erosive. Lesions detected in calves were characterised as papules (Fig. 1 and 2). Histopathological examination of surgically obtained sample was characterised with ballooning and degeneration of the epithelial cells and cytoplasmic viral inclusions. According to clinical and histopathological findings, bovine papular sto-

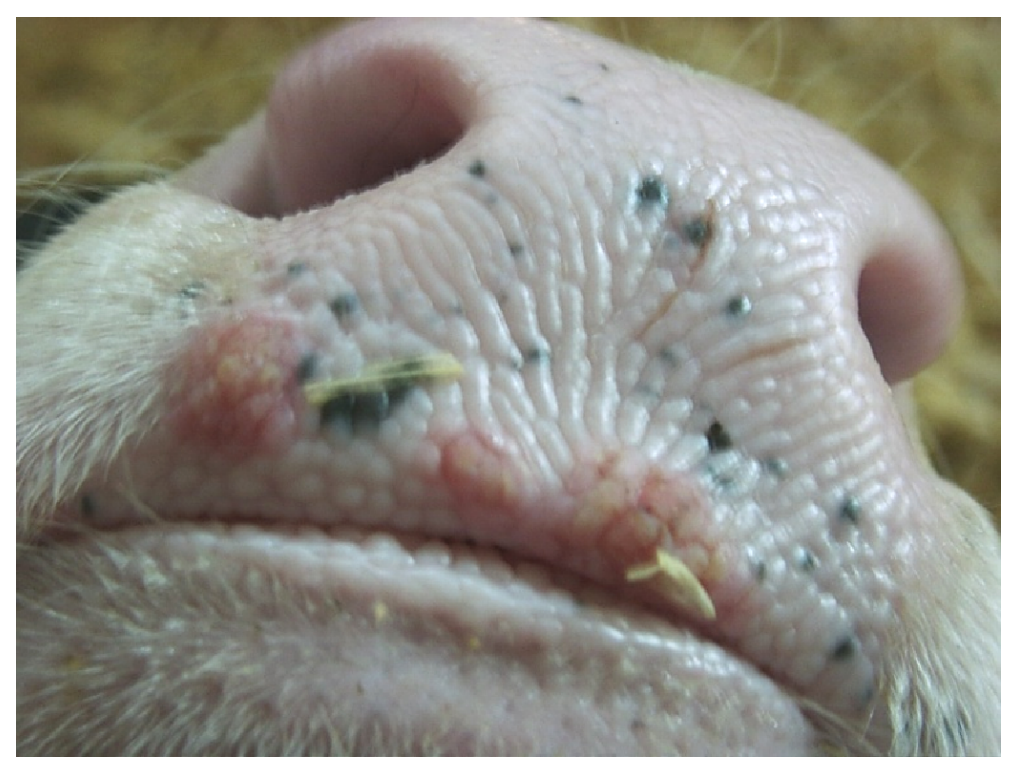

Fig. 1. Appearance of papules around the upper lip. 


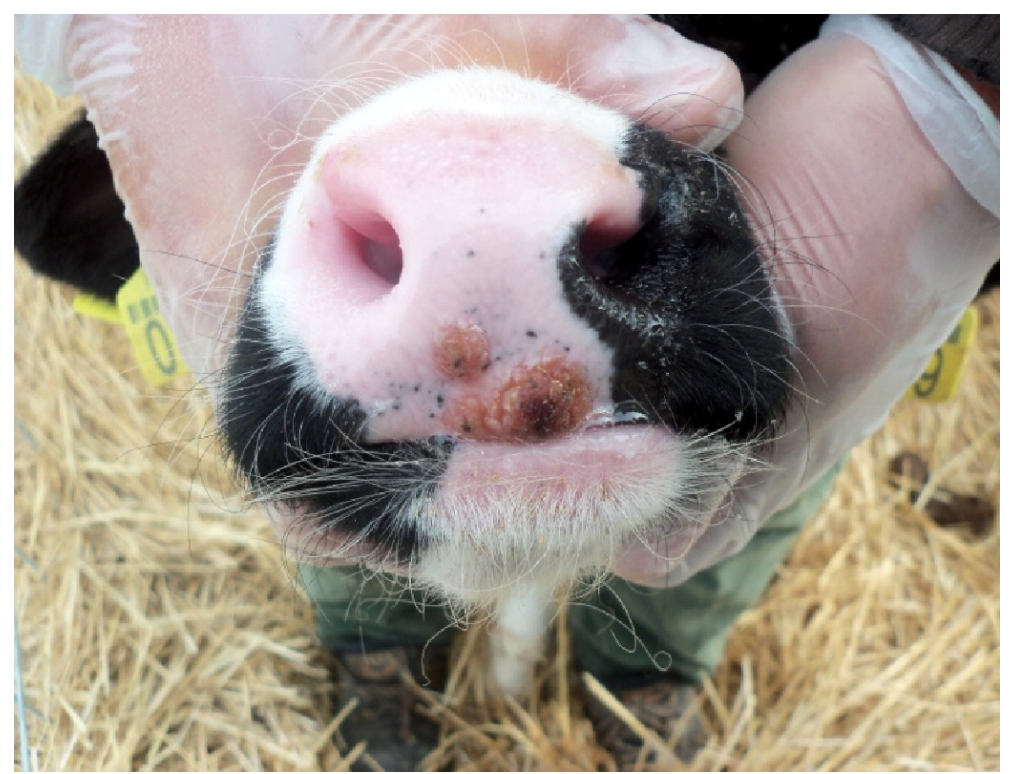

Fig. 2. Crusted papules around the upper lip of calf infected with bovine papular stomatitis.

matitis was suspected as cause of the lesions.

Results of commercial rapid test (Speed ${ }^{\circledR}$ V-DIAR 4) used to determine the agent responsible for the calf diarrhoea showed that 15 calves were positive for Cryptosporidium and 1 calf was positive for both Cryptosporidium and E.coli.

All 15 calves recovered within a period of two weeks after treatment. Suspected BPS lesions were observed to regress on day 2 after the second Zylexis ${ }^{\circledR}$ administration and were totally absent on the second week of the treatment. In addition calves suffering from pneumonia also recovered after the administration of antibiotic.

Diarrhoea of neonatal calves is a serious welfare problem and an important cause of economic loss for the cattle industry because of high mortality rates, treatment costs and poor growth. The etiology of calf diarrhoea is multifactorial and involves a wide range of infectious (bacterial, viral, protozoan) and noninfectious (enviromental, nutritional, etc.) factors (Al Mawly et al., 2015).

As mentioned above, Cryptosporidium is one of the main pathogens responsible for diarrhoea in calves. Clinical findings were characterised by mild diarrhoea and yellow faeces containing mucus. These findings are consistent with literature data about cryptosporidiosis.

The presented study is the second report of BPS in Turkey (Ozdemir et al., 2008). Disease has also been reported in USA, Africa and Europe (Radostits et al., 2006a). Histopathological examination revealed ballooning of the epithelial cells, this finding is observed and documented in many reports and is usually associated with poxvirus infections (Paton et al., 1990; Seo et al., 2005). Bohac \& Yates (1980) reported similar histopathological findings in calves suffering BPS with con- 
current bovine viral diarrhoea (BVD) infection. In the presented study, no virus isolation which is required for definitive diagnosis of BPS was performed. However, according to the histopathological findings and typical proliferative, round lesions with depressed grayish-brown centre and reddened periphery, the probable cause of stomatitis was BPS.

BPS is generally associated with concurrent diseases (Yosra et al., 2013). Bohac \& Yates (1980) reported BPS with concurrent BVD infection. Seifi et al. (2000) reported a case of BPS outbreak with concurrent coccidiosis. Presented study is the first report of BPS with concurrent Cryptosporidium infeciton.

Our case suggests that bovine papular stomatitis should be considered in the clinical diagnosis of calves presenting papule muzzle lesions in the ventral margins of the nares, on the buccal mucosa, inside the lips, and especially on the hard palate. In addition, concurrent infection with cryptosporidiosis could be related with failure of transfer of passive immunity or deleterious effects of cryptosporidiosis on immunity of calves.

In conclusion, BPS must be taken into consideration in calves with altered immunity and signs of cryptosporidiosis. Because of the zoonotic nature of both diseases, attention should be paid when clinical findings similar to BPS and cryptosporidiosis are observed.

\section{REFERENCES}

Al Mawly, J., A. Grinberg, D. Prattley, J. Moffat, J. Marshall \& N. French, 2015. Risk factors for neonatal calf diarrhoea and enteropathogen shedding in New Zealand dairy farms. The Veterinary Journal, 203, 155-160.

Bohac, J. G. \& W. D. G. Yates, 1980. Concurrent bovine virus diarrhea and bovine papular stomatitis infection in a calf. $\mathrm{Ca}$ nadian Veterinary Journal 21, 310-313.

Chalmers, R. M. \& F. Katzer, 2013. Looking for Cryptosporidium: The application of advances in detection and diagnosis. Trends in Parasitology, 29, 237-251.

Fabiano, J. F. S. A., E. R. Rogério, A. S. V. Valcinir, F. C. Juliana \& E. F. Flores, 2012. Bovine papular stomatitis affecting dairy cows and milkers in midwestern Brazil. Journal of Veterinary Diagnostic Investigation, 24, 442-445.

Oem, J. K., E. Y. Lee, K. K. Lee, S. H. Kim, M. H. Lee \& B. H. Hyun, 2013. Bovine papular stomatitis virus (BPSV) infections in Korean native cattle. Journal of Veterinary Medical Science 75, 675-678.

Ozdemir, O., M.Ortatatlı, F. Hatipoglu, H. Erer \& O. Yavuz, 2008. Yetmişbeş Günlük Bir Buzağıda Papüler Stomatitis Olgusu, IV. Ulusal Veteriner Patoloji Kongresi (Uluslar arası Katılıml1) 29 Ekim-2 Kasım 2008, Kemer/Antalya.

Paton, D. J., I. H. Brown, J. Fitton \& A. E. Wrathall, 1990. Congenital pig pox: A case report. The Veterinary Record, 127, 204.

Radostitis, O. M., C. C. Gay, D. C Blood \& K. W. Hinchcliff, 2006a. Bovine papullar stomatitis In: Veterinary Medicine: A Textbook of Diseases of Cows, Sheep, Pigs, Goats and Horses. Baillaire Tindall Publications, London, p. 1277.

Radostitis, O. M., C. C. Gay, D. C Blood \& K. W. Hinchcliff, 2006b. Cryptosporidiosis In: Veterinary Medicine: A Textbook of Diseases of Cows, Sheep, Pigs, Goats and Horses. Baillaire Tindall Publications, London, pp. 1512-1515.

Seifi, H. A., A. R. Movassaghi, M. Mohri, M. Rad, M. R. Aslani, A. Parand \& G. H. Razmi, 2000. Concurrent coccidiosis and bovine papular stomatitis infection in calves. Journal of Applied Animal Research, 18, 103-108.

Seo, P. S., N. H. Yoon \& S. D. Park, 2005. A clinical study of chicken pox in adoles- 
S. Senturk, S. Catık, E. M. Temizel \& O. Ozyigit

cents and adults. Korean Journal of Dermatology, 43, 933-938.

Yosra, A. H., K. Jürgen, N. Karsten, S. H. Georg \& K. H. Zessin, 2013. Molecular epidemiology of Cryptosporidium in livestock animals and humans in the Ismailia province of Egypt. Veterinary Parasitology, 193, 15-24.

Paper received 20.04.2015; accepted for publication 15.06.2015

\section{Correspondence:}

S. Catik

Department of Internal Medicine,

Faculty of Veterinary Medicine,

Uludag University,

Gorukle 16059 Bursa, Turkey

Tel: +902242940807

Fax: +902242940873

e-mail: serkancatik@uludag.edu.tr 